\title{
AVALIAÇÃO DA INFLUENCIA DA GRANULOMETRIA NA AÇÃO DO HEXAMETAFOSFATO DE SÓDIO EM REJEITO DA BAUXITA DE PARAGOMINAS-PA
}

\author{
S. G. e GONÇALVES ${ }^{1}$, K.F.CASTRO ${ }^{1}$, S. M. BRUM ${ }^{1}$, J.A.S. SOUZA ${ }^{1}$, A.M.P.F. FELIPE ${ }^{1}$ \\ ${ }^{1}$ Universidade Federal do Pará, Faculdade de Engenharia Química \\ E-mail para contato: silvane_gg@hotmail.com
}

\begin{abstract}
RESUMO - Na mineração da bauxita no município de Paragominas-PA, são descartados no processo de beneficiamento rejeitos com teor de sólido de 33,5\% e granulometria muito fina com $\mathrm{D}_{50}$ abaixo de $5 \mu \mathrm{m}$. Esses fatores contribuem para que esta suspensão apresente aumento na viscosidade e na tensão inicial de escoamento, fatores importantes durante o processo de bombeamento. Foi realizada análise granulométrica e determinadas as composições químicas e mineralógicas do material. Identificou-se $21,28 \%$ de alumina aproveitável e como princais minerais gibsita, hematita, quartzo e caulinita. Avaliou-se a influencia da granulometria do rejeito na ação do dispersante hexametafosfato de sódio. Os resultados mostraram-se favoráveis ao uso do hexametafosfato como dispersante na amostra sem tratamento. Entretanto a redução da granulometria apesar de potencializar a ação do aditivo não reduziu a viscosidade aparente a valores inferiores aos obtidos na amostra não tratada.
\end{abstract}

\section{INTRODUÇÃO}

A Mina de bauxita de Paragominas está localizada a $64 \mathrm{Km}$ do centro urbano da cidade de Paragominas, no nordeste do estado do Pará, e a $350 \mathrm{Km}$ da capital Belém. A atividade na mina começou em 2007 e atualmente é a terceira maior mina de bauxita no mundo, com capacidade de produção atual de 9,9 milhões de toneladas anuais. A Hydro é proprietária de $67,9 \%$ da Mineração Paragominas, os outros 32,1 \% são de propriedade da companhia brasileira Vale (Hydro, 2013).

Em paragominas, a bauxita ocorre em platôs (terrenos elevados e planos). Alguns, como o chamado Miltônia, a cerca de $60 \mathrm{~km}$, tem uma camada de bauxita em torno de 2 metros de espessura, coberta com uma camada estéril, principalmente de argila, que tem em média, 11 metros sobre o platô (Vale, 2013).

Nas atividades de mineração a lavra é inteiramente mecanizada, sem uso de explosivos e prevê não apenas a recomposição da área lavrada, com reposição do solo retirado, como o 
reflorestamento, com plantio de espécies nativas. O beneficiamento é feito por meio da lavagem da bauxita bruta, a fim de remover argila e areia fina. Estas partículas, normalmente, são consideradas uma fração indesejável, diminuindo o valor agregado do produto final, e encontram-se aderidas às partículas minerais de maior tamanho, sendo imprescindível a sua retirada do processo. Muitas vezes, essa contaminação por finos encontra-se na forma de aglomerados, que necessitam ser quebrados, dissolvidos e, por fim, separados da fração grossa. A suspensão resultante da lavagem é descartada como rejeito com baixa porcentagem de sólidos em barragens. Cerca de 70 a 75\% da massa é produto (Quaresma, 2009; Varela, 2009).

\section{MATERIAIS E MÉTODOS}

A amostra de rejeito de bauxita é oriunda da usina de beneficiamento da Mina de Bauxita de Paragominas no estado do Pará, com teor de sólido de 33,5 \% e pH 6,5.

Obteve-se a granulometria da amostra por peneiramento a úmido em um conjunto suspenso de malhas da escala Tyler e para as frações finas utilizou-se técnica da difração a laser em dois modelos Mastersizer 2000 da MalvernInstruments.

A composição química foi determinada por Espectrometria de Fluorescência de Raio-x, utilizando espectrômetro WDS sequencial, modelo AxiosMinerals. As aquisições e tratamento dos dados foram realizados no software SuperQ Manager. Para a determinação do conteúdo de $\mathrm{Al}_{2} \mathrm{O}_{3}$ aproveitável e de $\mathrm{SiO}_{2}$ reativa utilizou-se a metodologia adotada em Hollitt et al. (2001).

A análise de Difração de Raio-X (DRX) foi realizada no difratômetro de raios-X do modelo X'Pert Pro MPD (PW 3040/60). O resultado foi interpretado no programa X'Pert HighScore.

Utilizou-se o viscosímetro Hake modelo VT 550 com sensor tipo cilindros coaxiais SV1, para a elaboração dos ensaios de viscosidade. A programação foi taxa de cisalhamento de $100 \mathrm{~s}^{-1}$ e um tempo de 20s. Os ensaios foram realizados utilizando-se diferentes concentrações de hexametafosfato de sódio: $0 ; 0,5 ; 1 ; 1,5 ; 2 ; 2,5 ; 3 ; 4 ; 5$. Os testes foram realizados em amostras com a mesma granulometria oriunda da mina e em amostras passante na malha de 400\# Tyler, \% correspondendo a granulometria inferior a $38 \mu \mathrm{m}$.

\section{RESULTADOS E DISCUSSÃO}

A Tabela 1 apresenta o resultado da análise físico-química do rejeito e da bauxita de Paragominas. Pelo resultado observa-se que há a presença de 21,28\% de alumina aproveitável no descarte das frações finas.

Tabela 1 - Caracterização Físico-Química

\begin{tabular}{cc}
\hline Composição & Rejeito da Bauxita (\%) \\
\hline $\mathrm{Al}_{2} \mathrm{O}_{3}$ Aproveitável & 21,28 \\
\hline
\end{tabular}




\begin{tabular}{cc}
\hline $\mathrm{SiO}_{2}$ Reativa & 20,03 \\
$\mathrm{Al}_{2} \mathrm{O}_{3}$ Total & 43,38 \\
$\mathrm{Fe}_{2} \mathrm{O}_{3 \text { Total }}$ & 13,80 \\
$\mathrm{SiO}_{2}$ Total & 21,04 \\
$\mathrm{TiO}_{2}$ Total & 2,01 \\
PPC & 19,92 \\
$\mathrm{FE}($ Fechamento $)$ & 100,13 \\
\hline
\end{tabular}

A Figura 1 apresenta os resultados para a análise granulométrica. Observou-se a predominância de partículas bastante finas na amostra, apresentando um $\mathrm{d}_{50}$ abaixo de $5 \mu \mathrm{m}$.

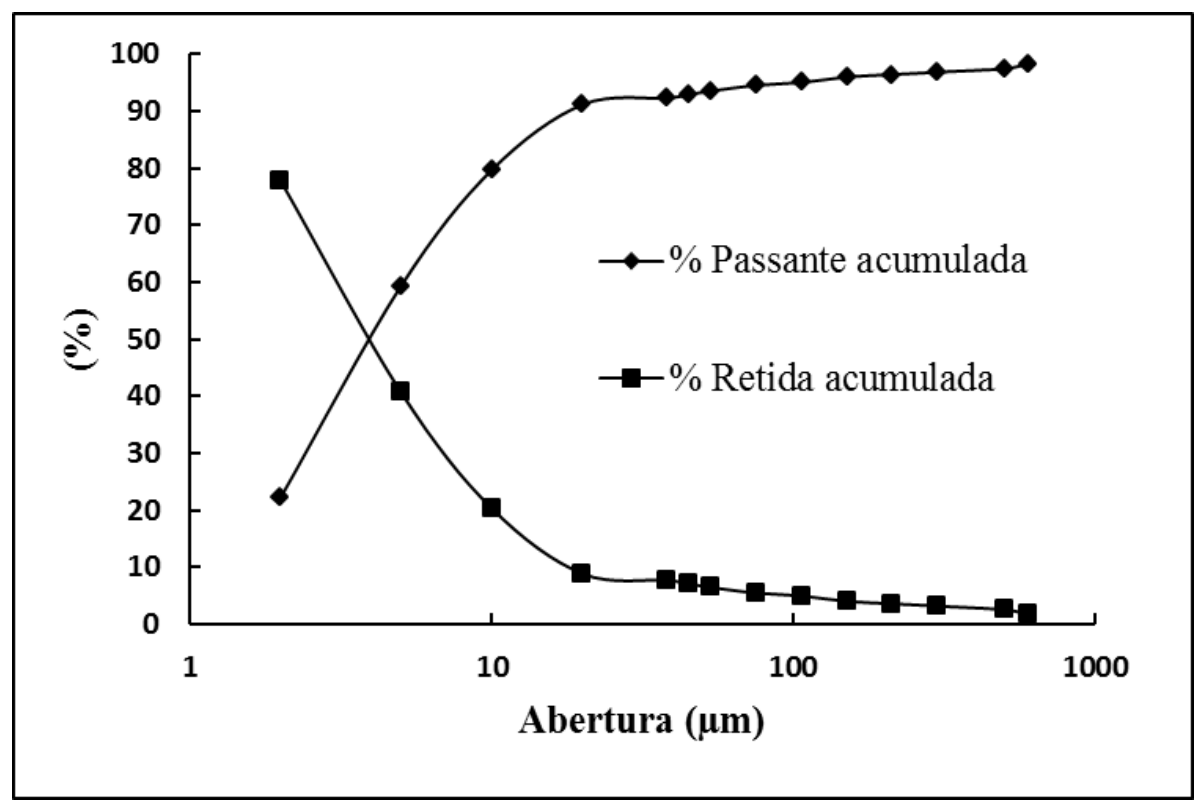

Figura 1 - Análise granulométrica do rejeito da bauxita.

A análise de Difração de Raios-x (Figura 2) identificou as seguintes composições minerais: gibsita, hematita, quartzo e caulinita. 


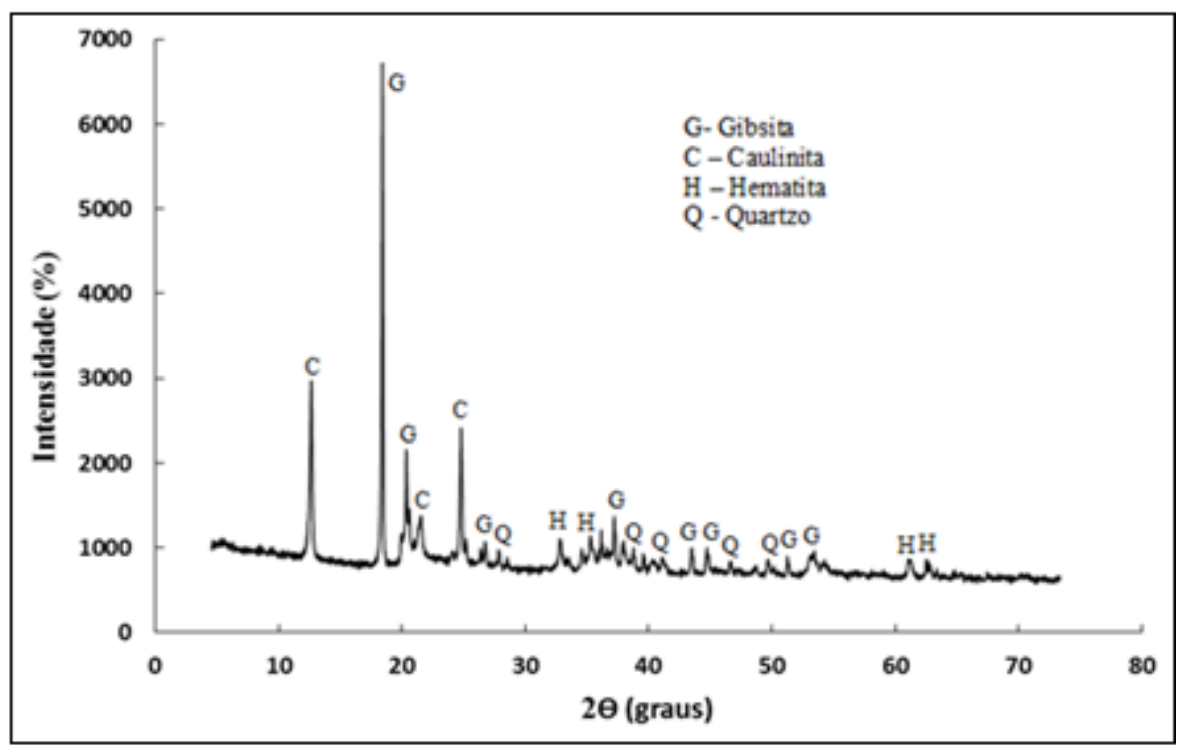

Figura 2 - Difratograma do rejeito da bauxita.

A adição de diferentes quantidades de hexametafosfato de sódio (Figura 3) apresentou ponto mínimo para a adição de $101,75 \mathrm{~g} /$ ton do defloculante. A redução da viscosidade aparente foi de $8,9 \%$, obtendo-se um valor final de 0,483 Pa.s.

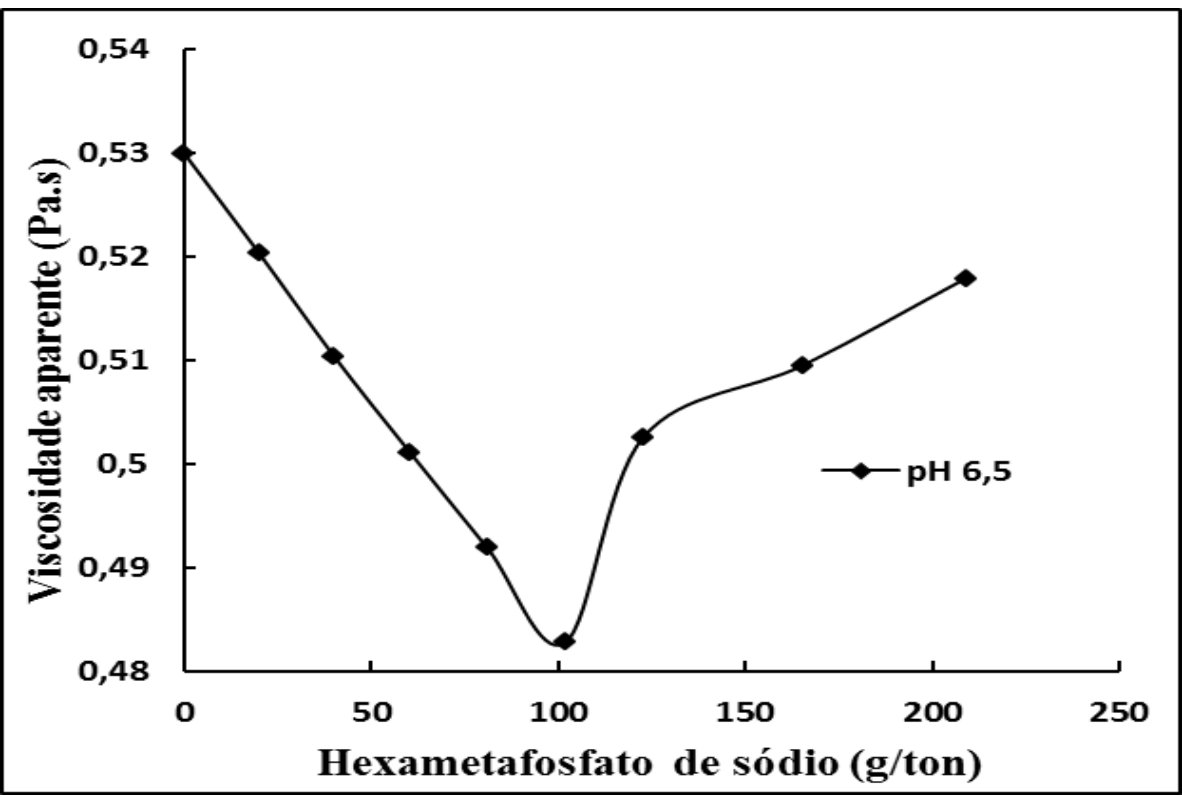

Figura 3 - Curva de defloculação com hexametafosfato de sódio.

Como a suspensão possui quantidade considerável de óxidos de alumínio (Tabela 1), a defloculação ocasionada pelo hexametafosfato de sódio pode ter ocorrido de acordo com as considerações feitas por Andreola et al. (2004) para o caso da argila. Nesse mecanismo os ânions do hexametafosfato de sódio interagem com os átomos expostos de alumínio, surgindo um complexo aniônico. $\mathrm{O}$ aumento de carga superficial negativa aumenta a força de repulsão entre as partículas e causa a defloculação. O hexametafosfato de sódio pode atuar também 
através da substituição dos cátions floculantes que podem estar dissolvidos por cátions $\mathrm{Na}$, adsorvendo nas partículas de argila, aumentando a espessura da dupla camada elétrica e causando a dispersão (Andreola et al., 2004; Rodrigues Neto et al., 2002).

A fração abaixo da malha 400\# Tyler (Figura 4), potencializou a ação do hexametafosfato de sódio, reduzindo a viscosidade aparente em $13,88 \%$ e o ponto mínimo de defloculação foi obtido para a adição de $60,43 \mathrm{~g} /$ ton, resultado inferior ao encontrado para o rejeito normal (Figura 3).

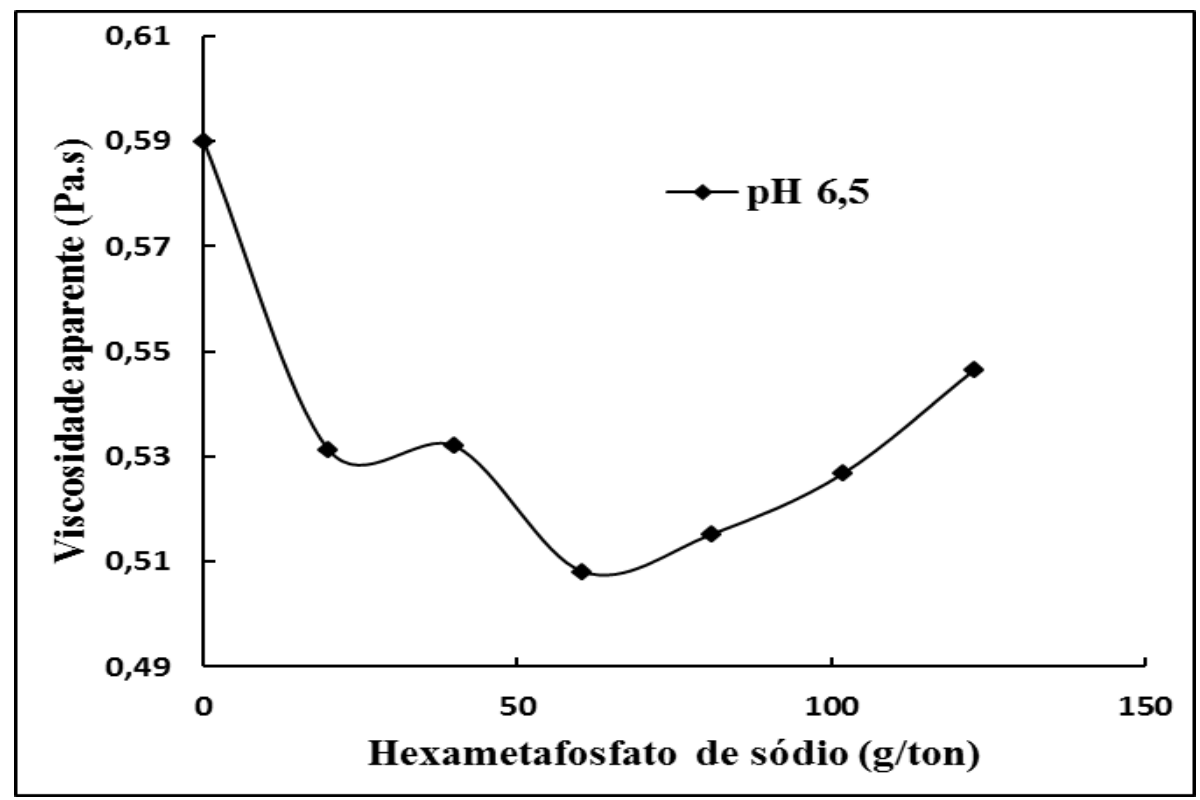

Figura 4 - Curva de defloculação com hexametafosfato de sódio (passante a 400\#Tyler).

Entretanto, apesar da redução da granulometria potencializar a ação do aditivo o resultado obtido para a viscosidade aparente, 0,508 Pa.s, foi superior ao obtido para a amostra não peneirada. Isso aconteceu devido às análises terem sido realizadas a 33,5\% de teor de sólido. Com isso o aumento na concentração de finos na amostra peneirada aumenta a viscosidade aparente inicial do rejeito e a redução em 13,88\% na viscosidade não foi suficiente para obter um valor inferior na viscosidade na mostra não peneirada.

\section{CONCLUSÃO}

Apesar da redução da granulometria potencializar a ação do aditivo, ela aumenta a concentração de finos na suspensão, aumentando a viscosidade aparente inicial. Com isso, observou-se que o dispersante utilizado na amostra passante a 400\# Tyler não reduziu a viscosidade aparente a valores inferiores aos obtidos na amostra não peneirada.

\section{AGRADECIMENTOS}

Ao CNPq pelo apoio financeiro concedido e as empresas Vale e Hydro pelo amostra cedida. 


\section{REFERÊNCIAS}

ANDREOLA, F; CASTELLINIB, E.; MANFREDINIA, T.; ROMAGNOLIA, M. The role of sodium hexametaphosphate in the dissolution process of kaolinite and kaolin. Journ. Europ. Cer. S., Italy, v. 24, 2004.

COSTA, L. S. Caracterização Química de Bauxita. XIV Jornada de Iniciação Científica CETEM, 2006.

HYDRO. Disponível em: <http://www.hydro.com/pt/Aluminio/A-Hydro-no-Brasil/Sobre-aHydro/Escritorios/Paragominas/>. Acesso em: 15 de fevereiro de 2013.

HOLLITT; M. J.; CRISP; A. J. ; STAKER; W. S. ; ROE; G. M.; RODDA; D. P. Process for removing reactive silica from a bayer process feedstock. United States Patent Number 6,309,615, 2001.

QUARESMA, L. F. Relatório Técnico 22. Ministério de Minas e Energia. 2009.

RODRIGUES NETO, J. B.; OLIVEIRA, A. P. N.; ALARCON, O. E.; POZZI, P.; ANDREOLA, F. Comparative study of deflocculation mechanisms in colloidal clay suspensions. Qualicer, Spain, 2002.

VALE. Disponível em:

$<$ http://saladeimprensa.vale.com/pt/versao_impressao/prt_detail.asp?tipo=2\&id=11160

>. Acesso em: 15 de fevereiro de 2013

VARELA, J. J. Estado da arte do processo de lavagem de minérios: conceito, aplicação e desenvolvimento. In: Encontro Nacional de Tratamento de Minérios e Metalurgia Extrativa, 23. Anais... Porto alegre: Gramado, v. 1. p. 225- 232, 2009. 